\title{
A comparison of the ceiling effect between Berg Balance Scale and Mini-BESTest in a group of balance trained community-dwelling older adults
}

DOI: https://doi.org/10.5114/pq.2018.73368

\author{
Barbara Ban, France Sevšek, Darja Rugelj \\ Faculty of Health Sciences, University of Ljubljana, Ljubljana, Slovenia
}

\begin{abstract}
Introduction. The aim of the study was to examine the ceiling effect of Berg Balance Scale (BBS) and Mini-BESTest (MBT) and to determine the most difficult items of the two scales in a group of functionally fit older adults.

Methods. The total of 26 community-dwelling older adults were enrolled to the study. Their functional status and agility were evaluated with the 10-meter walk test and Four-Square Step Test, respectively, followed by the BBS and MBT. The descriptive statistics were used for data analysis.

Results. The participants' functional status and agility were higher than the reported normative values for the age group. The results of BBS indicated a very high ceiling effect; as many as $73.1 \%$ of participants obtained the highest score. When tested by MBT, only $3.8 \%$ reached the highest score of the scale. The ceiling effect difference between BBS and MBT was statistically significant $(p<0.001)$. The most difficult item was $360^{\circ}$ turning for BBS and Timed Up and Go test with a cognitive task for MBT. Conclusions. The MBT presents a significantly smaller ceiling effect and is therefore more suitable for assessing balance even for balance trained older adults. The most difficult items of the two scales, i.e. $360^{\circ}$ turning and Timed Up and Go test with a cognitive task, may be used as a short screening tool.

Key words: the elderly, balance measures, Berg Balance Scale, Mini-BESTest, ceiling effect
\end{abstract}

\section{Introduction}

Balance deficits can arise from impairments of the somatosensory, musculoskeletal, visual, and vestibular systems [1], and have a significant negative impact on mobility and functional independence. Furthermore, impaired balance increases the fall risk in older adults, as well as in individuals with chronic neurological conditions such as Parkinson's disease, stroke, or multiple sclerosis [2-4]. Approximately $30 \%$ of community-dwelling adults aged 65 years and older fall annually [5] and the fall rates increase up to $50 \%$ in individuals older than 80 years, while persons with chronic neurological conditions such as Parkinson's disease, stroke, or multiple sclerosis fall even more frequently, with annual fall rates reaching up to $70 \%[3,5]$. The most common and effective intervention to improve balance and decrease the risk of falls is multicomponent, balance-specific exercise $[5,6]$.

A variety of measures have been developed to assess balance and to monitor balance changes over time. Several of these measures have been evaluated for their ability to predict the risk of falls. One of the most commonly used measures is Berg Balance Scale (BBS) [7]. It was originally designed to assess the balance and risk of falls in community-dwelling older adults [8], older adults living in nursing homes, and people after an acute stroke [9]. The psychometric properties of BBS for community-dwelling older adults have been reported, exhibiting excellent test-retest (inter-class correlation coefficient $(I C C)=0.91)$ and inter-rater $(I C C=0.97)$ reliability [10] The original results were later revised by Marques et al. [11] in a group of community-dwelling older adults where lower ICC for inter-rater $(I C C=0.88)$ and test-retest $(I C C=0.50)$ reliability were reported. Additionally, a low sensitivity to change (effect size, 0.29; 95\% confidence interval, 0.19-0.44) and responsiveness (standardized response mean, 0.47; 95\% confidence interval, 0.27-0.70) were observed [12].

Normative BBS data for community-dwelling older adults have been published [13] and a minimal detectable change of 3 to 5 points has been reported [14]. Additionally, the cutoff scores for fall prediction have been determined [10]. It was, however, found later that BBS was unable to predict falls in a sample of community-dwelling older adults who were active and independent [15].

Since its introduction, BBS has been often considered a 'gold standard' for balance assessment, despite its limitations [16]. Firstly, the BBS places too little focus on gait and on the dynamic component of balance [5]. Thus, additional balance tests are required for complete balance assessment, which further burdens clinicians' time. Secondly, the ceiling effect, i.e. high percentage of individuals who reach the highest attainable score of the measure (the upper limit), was reported as $22.5 \%$ for community-dwelling older adults [12, $15,17]$. Such a large ceiling effect prevents the use of the tool in a group of more capable participants and/or when substantial improvement between the first and the following tests is observed $[12,18]$.

To address the majority of balance components, Horak et al. [19] developed the Balance Evaluation Systems Test (BESTest), which consists of 36 items and covers a broad

Correspondence address: Darja Rugelj, University of Ljubljana, Faculty of Health Sciences, Zdravstvena pot 5, 1000 Ljubljana, Slovenia, e-mail: darja.rugelj@zf.uni-lj.si

Received: 2017.10 .24

Accepted: 2017.12.11

Citation: Ban B, Sevšek F, Rugelj D. A comparison of the ceiling effect between Berg Balance Scale and Mini-BESTest in a group of balance trained community-dwelling older adults. Physiotherapy Quarterly. 2017;25(2):3-9; doi: https://doi.org/10.5114/pq.2018.73368. 
spectrum of performance tasks, including dynamic stability and gait. The BESTest was designed to evaluate 9 balance components that contribute to balance; however, it takes about 45 minutes to administer [20]. To address the problem of long administration time, a shorter version, the MiniBESTest (MBT), was developed by Franchignoni et al. [21]. The MBT refers to 8 balance components and consists of 14 balance tasks [16] and takes only about 15-20 minutes to administer [22]. The MBT has been validated, showing excellent inter-rater (ICC $\geqslant 0.91)$ and test-retest $(I C C \geq 0.88)$ reliability [22] with the minimal detectable change of 3.5 points and minimal clinically important change of 4 points [18]. The MBT ceiling effect was reported as non-existent or low $(2.1 \%)$ in individuals with various neurological conditions [18]. As the ceiling effect over $15 \%[23,24]$ or $20 \%$ [25-27] is considered to be significant, MBT shows high resistance to maximum scoring. However, the ceiling effect of the BBS and MBT for functionally fit older adults have not been reported.

The functional status of older adults may remain high well into advanced age and does not necessarily correspond to chronological age [28]. To maintain or improve the functional status, more and more older adults participate in some sort of balance maintenance or balance enhancement programs, where different types of balance specific exercises are performed [29]. For more functionally fit older adults, an assessment tool with no or very low ceiling effect is therefore needed to allow the evaluation of changes in time due to exercises or due to the decline resulting from aging or disease. For BBS, Godi et al. [18] reported that only individuals with severely limited balance function did not reach the ceiling of the scale. Their results indicate that BBS is not the first choice for balance assessment in the group of reasonably fit older adults. There is also a concern that the ceiling could be reached already at the baseline assessment, with the tool applied as an outcome measure for balance training.

The purpose of this study was to compare the ceiling effect of BBS and MBT in a group of balance trained communitydwelling older adults and to determine the most difficult items of each scale. We hypothesized that MBT would have lower ceiling effect as compared with BBS.

\section{Subjects and methods}

An observational within-subject study of community-dwelling older adults who participated for 10 months, twice weekly

Table 1. Participants' characteristics and functional status

\begin{tabular}{|c|c|c|c|}
\hline & Mean & $S D$ & Range \\
\hline \multicolumn{4}{|l|}{ Characteristics } \\
\hline Age (years) & 70.1 & 6.1 & $61-85$ \\
\hline Height (cm) & 163.6 & 7.5 & $150-180$ \\
\hline Weight (kg) & 66.5 & 11.6 & $48-90$ \\
\hline $\mathrm{BMI}\left(\mathrm{kg} / \mathrm{m}^{2}\right)$ & 24.9 & 2.9 & $18-33$ \\
\hline Reported previous injuries & 1.1 & 1.3 & $0-4$ \\
\hline Reported number of medications & 1.3 & 1.2 & $0-4$ \\
\hline \multicolumn{4}{|l|}{ Functional status } \\
\hline Weekly physical activity (days) & 5.4 & 1.4 & $1-7$ \\
\hline Walking speed (m/s) & 1.4 & 0.2 & $0.9-1.5$ \\
\hline Four-Square Step Test (s) & 7.5 & 1.2 & $5-10$ \\
\hline
\end{tabular}

in balance-specific exercise program was conducted. The inclusion criteria were healthy, independent daily life with the ability to walk downstairs, while the exclusion criteria were recent injury or condition affecting independent life. The total of 26 older adults were enrolled to the study, 23 females and 3 males, with the average age of $70.1 \pm 6.1$ years. Their descriptive data are presented in Table 1. Prior to the enrolment, the participants were informed of the study purpose and procedures.

\section{Balance program}

The balance-specific exercise program was organized as a multi-component program which has been described in detail elsewhere $[6,30]$. In brief, the following components of balance were emphasized: (1) changing of the centre of gravity (CoG) position; (2) shifting the CoG to the limits of stability; (3) rotation of head and body around the vertical axis; (4) standing and walking on a soft surface; (5) walking over obstacles or on a narrow path; (6) multitasking.

\section{Functional status measures}

To determine the functional status of the participants, their preferred walking speed and agility were evaluated. Walking speed has been namely shown to reflect the functional and physical health status of community-dwelling older adults [31]. The preferred walking speed $(\mathrm{m} / \mathrm{s})$ was assessed with a timed 10-meter walk test [32] in a well-lit corridor during a separate session. A 14-meter walkway was used, providing 2 additional meters of distance for both acceleration and deceleration, and trials were timed with a chronometer in the middle 10 meters [33]. The participants completed 3 consecutive trials, and the means of the trials were calculated. Excellent test-retest reliability (ICC > 0.93) of comfortable walking speed has been reported for healthy adults [32] and older community-dwelling adults [34].

The Four-Square Step Test (FSST) was used to assess agility, and was conducted prior to balance measures. FSST is a timed test that requires stepping over low obstacles ( $2.5 \mathrm{~cm}$ high) in 4 directions: forward, to the right, backward, and to the left. One practice trial and 2 timed trials were performed in clockwise direction, immediately followed by anticlockwise direction [35], and the fastest time of the timed trials was recorded. The trial was repeated if any of the obstacles was touched, balance was lost, or both feet were not placed in the square $[35,36]$. High inter-rater $(I C C=0.99)$ and test-retest $(\mathrm{ICC}=0.98)$ reliability in community-dwelling older adults have been reported [35]. Normative data are available for older adults in the age range of 70-80 years $(n=$ $20 ; 18.1 \pm 1.8 \mathrm{~s})$ and $60-70$ years $(n=20 ; 16.3 \pm 3.6 \mathrm{~s})$ [37], as well as for older adults residing in a nursing home $(n=20$; $23.9 \pm 14.5$ s) [38].

\section{Psychometric properties of the two evaluated balance measures}

BBS is a 14-item balance measure, rated on a 0 (very limited performance, needs assistance) to 4 (independent performance) scale, with the total of 56 points, where higher scores indicate 'better' balance. BBS requires participants to maintain positions of varying difficulty and to perform everyday tasks such as sit-to-stand transfer and single leg stance $[9,39]$. Persons with scores between 41 and 56 exhibit a low fall risk and can move independently, individuals with scores 21 to 40 present a medium fall risk and need assistance 
when walking, whereas scores between 0 and 20 refer to a high fall risk [10]. A more recently reported cut-off value for BBS fall prediction lower than 48.5 points was found to be predictive of falls ( $74 \%$ sensitivity, $72 \%$ specificity) in a group of community-dwelling older adults [11].

MBT is comprised of 14 items scored from 0 (cannot perform) to 2 (normal performance). For items \#3 (single-leg stance) and \#6 (compensatory lateral stepping), which are assessed bilaterally, the lowest of the 2 scores is included in the total score. For item \#14 (Timed Up and Go test [TUG] with a secondary cognitive task), gait slowing of more than $10 \%$ when compared with TUG time without a cognitive task means decreasing the score by 1 point. The maximum score for MBT is 28 points [18, 21, 39]. MBT cut-off scores for fall predictions in community-dwelling older adults have been reported by Marques et al. [11] as 19.5 points (74\% sensitivity, $71 \%$ specificity).

\section{Procedure}

The testing was performed by a post-graduate physiotherapy student trained in all testing procedures in the biomechanical laboratory of the Faculty of Health Sciences, University of Ljubljana, Slovenia. The gait speed was assessed in a separate session prior to balance testing. FSST was carried out in the same session as BBS and MBT. Out of the 2 compared balance measures, BBS was the first one completed by each participant, followed by MBT. Testing order was the same for all the individuals, as originally described [8-10, 21]. The participants did not require rest periods during testing.

\section{Data analysis}

The Statistical Package for Social Sciences (SPSS 23, SPSS Inc., Chicago, USA) was used for data analysis. Descriptive statistics were calculated for all measures. The ceiling effect of BBS and MBT was determined by calculating the percentage of participants obtaining the maximal score. Additionally, significance was determined with the McNemar test. According to several authors, ceiling effect may be considered as significant when more than $20 \%$ of the tested individuals reach the maximal score of the scale [25-27] while others set this limit to $15 \%[23,24]$. Individual items of BBS and MBT were further analysed and the percentages of the participants who achieved the maximal score were calculated.

\section{Ethical approval}

The research related to human use has been complied with all the relevant national regulations and institutional policies, has followed the tenets of the Declaration of Helsinki, and has been approved by the Slovenian Medical Ethics Committee (Ministry of Health, Ljubljana, Slovenia).

\section{Informed consent}

Informed consent has been obtained from all individuals included in this study.

\section{Results}

The preferred walking speed (Table 1) was up to $21 \%$ (range 11-21\%) faster than the one reported in the normative data for that age group [32]. The participants' agility, as determined by FSST (Table 1), turned out better than that reported in the normative data [37], indicating higher than average agility of the group.

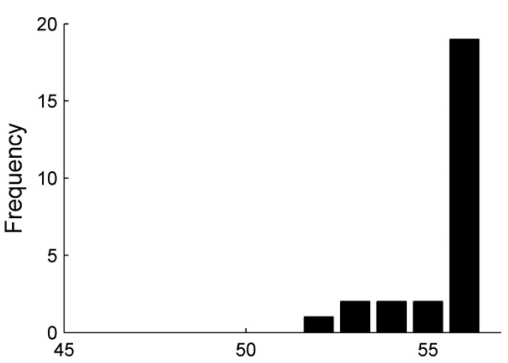

(a) Berg Balance Scale score

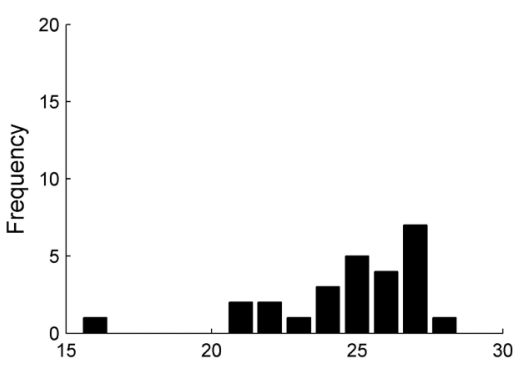

(b) Mini-BESTest score

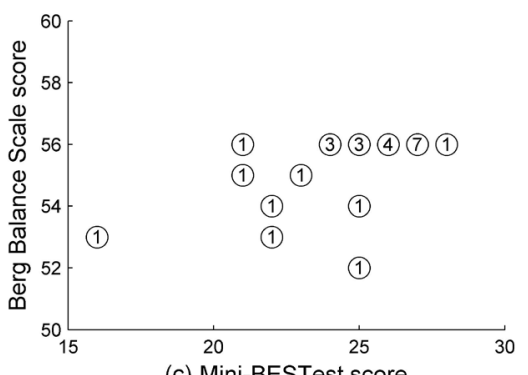

(c) Mini-BESTest score

Figure 1. Distribution of scores for (a) the Berg Balance Scale and (b) Mini-BESTest, together with (c) a scatter plot showing the relationship between Berg Balance Scale and Mini-BESTest, where figures indicate the numbers of participants with the same score. The axes were adjusted so that most of the areas with no data points were omitted

The descriptive statistics for the balance tests in the group of fit older participants were: mean BBS score, $55 \pm 1.2$ points (range, 52-56); mean MBT, $25 \pm 2.6$ points (range, 16-28). We further calculated the percentages of individuals who obtained the highest score for BBS and MBT. As shown in Figure 1a, 1b and 1c, BBS has a far larger ceiling effect than MBT since $73.1 \%$ (19) of the participants achieved the maximal total score of 56 points as measured with BBS and only $3.9 \%$ (1) of the participants obtained the maximal 28 points as measured with MBT. Those participants who achieved the maximal number of points when assessed with BBS were further analysed for the distribution of their MBT scores. Out of those 19 participants, 1 person $(5.3 \%)$ reached the maximal score of 28 points with MBT, 7 (36.8\%) obtained 27 points, $4(21.0 \%) 26$ points, $3(15.8 \%) 25$ points and 24 points, and 1 of them (5.3\%) obtained the lowest score of 21 points (Figure 1c). The percentage of participants who achieved the maximal number of points when assessed with BBS was significantly higher as compared with MBT (McNemar's $p<0.001)$.

\section{Distribution of scores and relationship between BBS and MBT}

For the purpose of presenting the order of most difficult items of the 2 applied balance tests, the individual items of $\mathrm{BBS}$ and MBT were ranked on the basis of the percentage 
Table 2. Individual items of the Berg Balance Scale and Mini-BESTest ranked from the most to least difficult on the basis of the percentage of participants who failed to attain the maximal score

\begin{tabular}{|c|c|c|c|}
\hline Berg Balance Scale item & $\begin{array}{l}\text { Level of difficulty } \\
\text { (\% of failures) }\end{array}$ & Mini-BESTest item & $\begin{array}{l}\text { Level of difficulty } \\
\text { (\% of failures) }\end{array}$ \\
\hline Turning by $360^{\circ}$ & 23.1 & TUG, cognitive & 80.8 \\
\hline Tandem stance & 15.4 & Compensatory stepping, backward & 38.5 \\
\hline Reaching forward & 7.7 & Gait with pivot turn & 38.5 \\
\hline One leg stance & 3.9 & Rise to toes & 32.3 \\
\hline Stepping & 0 & One leg stance & 30.8 \\
\hline Looking backwards & 0 & Compensatory stepping, lateral & 26.9 \\
\hline Retrieving object from the floor & 0 & Eyes closed foam & 19.2 \\
\hline Standing with feet together & 0 & Changing of gait speed & 11.5 \\
\hline Standing with eyes closed & 0 & Obstacle crossing & 3.9 \\
\hline Sitting from chair to chair & 0 & Turning head during gate & 3.9 \\
\hline Sitting down & 0 & Compensatory stepping, forward & 3.9 \\
\hline Standing up & 0 & Inclined surface, eyes closed & 3.9 \\
\hline Unsupported standing & 0 & Eyes open stance & 0 \\
\hline Unsupported sitting & 0 & Sit to stand & 0 \\
\hline
\end{tabular}

TUG - Timed Up and Go test

of participants who did not achieve the maximal score in that particular item (Table 2). The results show that the most difficult balance item in BBS was $360^{\circ}$ turning $(23.1 \%$ of the participants did not achieve the maximum score of 4). For the MBT, the dual task proved to be the most difficult item, with $80.8 \%$ of the participants not obtaining the maximal score of 2 . The second most difficult item of MBT was compensatory stepping backwards (the participant leans backwards into the therapist's hands and the support is suddenly released), with $38.5 \%$ of the participants who did not achieve the maximal score, followed by gait with pivot turn (walking and, on command, stopping and making a $180^{\circ}$ turn); the fourth place with regard to difficulty in MBT was rise to toes $(32.3 \%$ of the participants did not achieve the score of 2). The detailed ranking of individual items for both scales is presented in Table 2.

\section{Discussion}

The purpose of the paper was to evaluate and compare the ceiling effects of BBS and MBT and to determine the most difficult items of both balance scales in a group of communitydwelling older adults with high functional status. The results show that MBT has a significantly smaller ceiling effect as compared with BBS. In the group of participants, only $3.8 \%$ reached the maximal score when tested with $\mathrm{MBT}$ and as many as $73.1 \%$ when tested with BBS. No previous studies reported such a high ceiling effect of BBS although the ceiling effect of BBS was determined in various populations, such as community-dwelling older adults [11, 12, 15, 17], individuals with chronic stroke [27, 40, 41], persons with paraplegia and tetraplegia [42], individuals with Parkinson's disease [34, 39] and multiple sclerosis [43], with the results ranging from $22.5 \%$ to $38 \%$. For a group of patients with balance disorders, Godi et al. [18] reported a pronounced ceiling effect after finishing an exercise program, indicating tient groups. The differences between previous reports and the current one can be attributed to a very high functional status of our group.

The studies on the ceiling effect of MBT are few. Godi et al. [18] observed a significantly lower ceiling effect for MBT (10\%) as compared with BBS (50\%). King et al. [39] also reported a significantly lower ceiling effect of MBT in a group of patients with mild Parkinson's disease. Our study is the first documented assessment of the ceiling effect of MBT in a group of older adults with very high functional status.

MBT was designed to overcome the weakness of other established balance tests, including BBS, which predominantly assess the static domain of balance [16]. According to the Systems Framework for Postural Control, the 2 balance tests used in our study include different numbers of balance components from the 9 proposed ones (static stability, underlying motor systems, functional stability limits, verticality, reactive postural control, anticipatory postural control, dynamic stability, sensory integration, cognitive influences) [16]. Out of the 2 assessed balance measures, BBS refers to 6 components and MBT includes 8 balance components. The overlapping components of both tests are static stability, underlying motor systems, anticipatory postural control, dynamic stability, and sensory integration; whereas verticality, reactive postural control, and cognitive influences are components assessed only by MBT, and functional stability limits are included in BBS only [16].

The most difficult items (individual items where the highest percentage of participants did not achieve the maximal score) of MBT and BBS indicate 3 balance components: cognitive (dual tasking), assessed only by MBT, as well as dynamic balance and reduced base of support, determined by both scales. In the present group, the most demanding item of MBT was the TUG test with a cognitive task, with $80.8 \%$ of sub-maximal results. Only 5 participants (19.2\%) decreased their walking speed for less than $10 \%$ without errors in the concurrent subtraction task. These results are in agreement 
with the previous research by Hausdorff et al. [44], who reported that $93 \%$ of older adults demonstrated a decrease of preferred walking speed when a subtraction task was added. The observed changes of TUG with an additional cognitive task vary between studies. Toulotte et al. [45] noted a $4 \%$ increase of time for non-fallers and $12 \%$ for fallers. In that study, as in ours, the preferred walking speed was used, while Shumway-Cook et al. [46] assessed fast walking speed and reported a $15 \%$ increase of time to complete the TUG test.

The most demanding item of the BBS was turning by $360^{\circ}$, where $23.1 \%$ of the participants did not achieve the maximal score, indicating slowness in turning around the vertical axis. This movement is a part of everyday functional activities, such as changing walking direction or changing siting positions (e.g. from chair to chair or from chair to bed), and requires, besides weight shift, also additional stabilization of gaze. Turning by $360^{\circ}$ is usually not the last item tested with BBS. Our results indicate that the order of tasks within the scale should be changed if the concept of increasing difficulty is to be followed. Turning by $360^{\circ}$ as an independent performance measure has been found to be able to predict the onset of functional dependency [47]. It has been recommended as part of standard performance test battery for early identifying functional decline [48]. The present results indicate that turning by $360^{\circ}$ and cognitive TUG could be used as a short screening tool for detecting early discrete balance impairments in a group of highly functional elderly to whom specific balance training could be advised.

BBS is often applied as a functional outcome measure for balance specific exercise programs [12, 30, 49, 50]. However, the recommendations for exercise and physical activity for older adults to maintain balance emphasize increased activity also among those whose functional decline may not yet be significant [29]. Therefore, an increase in the numbers of fit older adults who participate in balance maintenance programs has indicated a need for scales with more balance demanding items. Although the reported convergent [18] and concurrent [11] validity of BBS and MBT are high, the lower ceiling effect of MBT points at its higher suitability for the assessment of older persons with still well-preserved balance [18]. MBT responsiveness to change has been reported for patients with different balance disorders [18], while its responsiveness to change for the community-dwelling older adults with high functional status needs to be further established.

\section{Limitations}

The main limitation of the present study is its rather small sample size. However, given the validity of MBT established by Franchignoni et al. [21] and Pardasaney et al. [12], availability of normative values as in O'Hoski et al. [51], and the ceiling effect of the 2 evaluated scales determined in different populations by King et al. [39] and Godi et al. [18], who worked with groups of comparable size, it is expected that this study will add to the body of knowledge on the metric properties of the assessed scales. A convenient sample as described in the present work can also be considered as a limitation. As we were primarily interested in the ceiling effect of the tests in balance trained individuals, only posttraining measurements were performed, which may constitute an additional limitation of the study.

\section{Conclusions}

MBT presents a low ceiling effect despite the fact that the assessed group of older adults displayed high functional abilities and was balance trained, while BBS has a very high ceiling effect in the same group of participants. Given the responsiveness of $\mathrm{MBT}$ for patients with balance disorders established by Godi et al. [18] and a low ceiling effect of MBT as indicated by the present study, MBT may be more suitable than BBS as an outcome measure for balance specific exercise programs for healthy community-dwelling older adults.

\section{Disclosure statement}

No author has any financial interest or received any financial benefit from this research.

\section{Conflict of interest}

The authors state no conflict of interest.

\section{References}

1. Segev-Jacubovski O, Herman T, Yogev-Seligmann G, Mirelman A, Giladi N, Hausdorff JM. The interplay between gait, falls and cognition: can cognitive therapy reduce fall risk? Expert Rev Neurother. 2011;11(7):1057-1075; doi: 10.1586/ern.11.69.

2. Weaver TB, Robinovitch SN, Laing AC, Yang YJ. Falls and Parkinson's disease: evidence from video recordings of actual fall events. J Am Geriatr Soc. 2016;64(1): 96-101; doi: 10.1111/jgs.13878.

3. Liphart J, Gallichio J, Tilson JK, Pei Q, Wu SS, Duncan PW. Concordance and discordance between measured and perceived balance and the effect on gait speed and falls following stroke. Clin Rehabil. 2016;30(3):294-302; doi: 10.1177/0269215515578294.

4. Mazumder R, Lambert WE, Nguyen T, Bourdette DN, Cameron $\mathrm{MH}$. Fear of falling is associated with recurrent falls in people with multiple sclerosis: a longitudinal cohort study. Int J MS Care. 2015;17(4):164-170; doi: 10.7224/1537-2073.2014-042.

5. Ambrose AF, Paul G, Hausdorff JM. Risk factors for falls among older adults: a review of the literature. Maturitas. 2013;75(1):51-61; doi:10.1016/j.maturitas.2013.02.009.

6. Rugelj D. The effect of functional balance training in frail nursing home residents. Arch Gerontol Geriatr. 2010;50(2):192-197; doi: 10.1016/j.archger.2009.03.009.

7. Howe T, Rochester L, Neil F, Skelton DA, Ballinger C. Exercise for improving balance in older people. Cochrane Database Syst Rev. 2011;(11):CD004963; doi: 10.1002/ 14651858.CD004963.pub3.

8. Berg K, Wood-Dauphinée S, Williams JI, Gayton D. Measuring balance in the elderly: preliminary development of an instrument. Physiother Can. 1989;41(6):304311; doi: 10.3138/ptc.41.6.304.

9. Berg K, Wood-Dauphinée S, Williams JI. The Balance Scale: reliability assessment with elderly residents and patients with an acute stroke. Scand $\mathrm{J}$ Rehabil Med. 1995;27(1):27-36.

10. Berg K, Wood-Dauphinée S, Williams JI, Maki B. Measuring balance in the elderly: validation of an instrument. Can J Public Health. 1992;83(Suppl 2):S7-S11.

11. Marques A, Almeida S, Carvalho J, Cruz J, Oliveira A, Jácome C. Reliability, validity, and ability to identify fall status of the Balance Evaluation Systems Test, MiniBalance Evaluation Systems Test, and Brief-Balance Evaluation Systems Test in older people living in the community. Arch Phys Med Rehabil. 2016;97(12):21662173,e1; doi: 10.1016/j.apmr.2016.07.011. 
12. Pardasaney PK, Latham NK, Jette AM, Wagenaar RC, $\mathrm{Ni} P$, Slavin MD, et al. Sensitivity to change and responsiveness of four balance measures for community-dwelling older adults. Phys Ther. 2012;92(3):388-397; doi: 10.2522/ptj.20100398.

13. Steffen TM, Hacker TA, Mollinger L. Age- and gender-related test performance in community-dwelling elderly people: Six-Minute Walk Test, Berg Balance Scale, Timed Up \& Go Test, and gait speeds. Phys Ther. 2002;82(2): 128-137; doi: 10.1093/ptj/82.2.128.

14. Donoghue D, Physiotherapy Research and Older People (PROP) group, Stokes EK. How much change is true change? The minimum detectable change of the Berg Balance Scale in elderly people. J Rehabil Med. 2009; 41(5):343-346; doi: 10.2340/16501977-0337.

15. Boulgarides LK, McGinty SM, Willett JA, Barnes CW. Use of clinical and impairment-based tests to predict falls by community-dwelling older adults. Phys Ther. 2003;83(4):328-339; doi: 10.1093/ptj/83.4.328.

16. Sibley KM, Beauchamp MK, Van Ooteghem K, Straus SE, Jaglal SB. Using the systems framework for postural control to analyze the components of balance evaluated in standardized balance measures: a scoping review. Arch Phys Med Rehabil. 2015;96(1):122-132.e29; doi: 10.1016/j.apmr.2014.06.021.

17. Balasubramanian CK. The community balance and mobility scale alleviates the ceiling effects observed in the currently used gait and balance assessments for the community-dwelling older adults. J Geriatr Phys Ther. 2015; 38(2):78-89; doi: 10.1519/JPT.0000000000000024.

18. Godi M, Franchignoni F, Caligari M, Giordano A, Turcato AM, Nardone A. Comparison of reliability, validity, and responsiveness of the Mini-BESTest and Berg Balance Scale in patients with balance disorders. Phys Ther. 2013;93(2):158-167; doi: 10.2522/ptj.20120171.

19. Horak FB, Wrisley DM, Frank J. The Balance Evaluation Systems Test (BESTest) to differentiate balance deficits. Phys Ther. 2009;89(5):484-498; doi: 10.2522/ptj.20080071.

20. Sibley KM, Howe T, Lamb SE, Lord SR, Maki BE, Rose DJ, et al. Recommendations for a core outcome set for measuring standing balance in adult populations: a consensus-based approach. PLoS One. 2015;10(3):e0120568; doi: 10.1371/journal.pone.0120568.

21. Franchignoni F, Horak F, Godi M, Nardone A, Giordano A. Using psychometric techniques to improve the Balance Evaluation Systems Test: the mini-BESTest. J Rehabil Med. 2010;42(4):323-331; doi: 10.2340/16501977-0537.

22. Leddy AL, Crowner BE, Earhart GM. Utility of the MiniBESTest, BESTest, and BESTest sections for balance assessments in individuals with Parkinson disease. J Neurol Phys Ther. 2011;35(2):90-97; doi: 10.1097/ NPT.0b013e31821a620c.

23. McHorney CA, Tarlov AR. Individual-patient monitoring in clinical practice: are available health status surveys adequate? Qual Life Res. 1995;4(4):293-307; doi: 10.1007/BF01593882.

24. Considine S. The concurrent validity of the 7-item BBS 3P with other clinical measures of balance in a sample of elderly community-dwelling adults (masters dissertation). Dublin: Royal College of Surgeons in Ireland; 2014.

25. Mao HF, Hsueh IP, Tang PF, Sheu CF, Hsieh CL. Analysis and comparison of the psychometric properties of three balance measures for stroke patients. Stroke. 2002;33(4): 1022-1027; doi: 10.1161/01.STR.0000012516.63191.c5.

26. Tyson SF, DeSouza LH. Development of the Brunel Balance Assessment: a new measure of balance dis- ability post stroke. Clin Rehabil. 2004;18(7):801-810; doi: 10.1191/0269215504cr744oa.

27. Blum L, Korner-Bitensky N. Usefulness of the Berg Balance Scale in stroke rehabilitation: a systematic review. Phys Ther. 2008;88(5):559-566; doi: 10.2522/ptj.20070205.

28. Shumway-Cook A, Woollacott MH. Motor control: translating research into clinical practice, $5^{\text {th }}$ ed. Philadelphia: Wolters Kluwer; 2017.

29. Chodzko-Zajko WJ, Proctor DN, Fiatarone Singh MA, Minson CT, Nigg CR, Salem GJ, et al. Exercise and physical activity for older adults. Med Sci Sports Exerc. 2009;41(7):1510-1530; doi:10.1249/MSS.0b013e3181 a0c95c.

30. Rugelj D, Tomšič M, Sevšek F. Do fallers and nonfallers equally benefit from balance specific exercise program? A pilot study. Biomed Res Int. 2013;2013:753298; doi: 10.1155/2013/753298.

31. Abellan van Kan G, Rolland Y, Andrieu S, Bauer J, Beauchet O, Bonnefoy M, et al. Gait speed at usual pace as a predictor of adverse outcomes in community-dwelling older people an International Academy on Nutrition and Aging (IANA) Task Force. J Nutr Health Aging. 2009; 13(10):881-889; doi: 10.1007/s12603-009-0246-z.

32. Bohannon RW. Comfortable and maximum walking speed of adults aged 20-79 years: reference values and determinants. Age Ageing. 1997;26(1):15-19; doi: 10.1093/ ageing/26.1.15.

33. Flansbjer UB, Holmbäck AM, Downham D, Patten C, Lexell $\mathrm{J}$. Reliability of gait performance tests in men and women with hemiparesis after stroke. J Rehabil Med. 2005;37(2):75-82; doi: 10.1080/16501970410017215.

34. Steffen T, Seney M. Test-retest reliability and minimal detectable change on balance and ambulation tests, the 36 -item short-form health survey, and the unified Parkinson disease rating scale in people with parkinsonism. Phys Ther. 2008;88(6):733-746; doi: 10.2522/ptj.20070214.

35. Dite W, Temple VA. A clinical test of stepping and change of direction to identify multiple falling older adults. Arch Phys Med Rehabil. 2002;83(11):1566-1571; doi: 10.1053/ apmr.2002.35469.

36. Whitney SL, Marchetti GF, Morris LO, Sparto PJ. The reliability and validity of the Four Square Step Test for people with balance deficits secondary to a vestibular disorder. Arch Phys Med Rehabil. 2007;88(1):99-104; doi: 10.1016/j.apmr.2006.10.027.

37. Choudhary R, Walia S, Noohu MM. Age and gender related test performance in community dwelling older adults on physical performance and balance. Indian $\mathrm{J}$ Gerontol. 2016;30(3):295-304.

38. Sonc N, Rugelj D. Normative values of Four Square Step Test [in Slovenian]. Fizioterapija. 2014;22(1):31-37. Available from: http://www.physio.si/wp-content/uploads/ 2016/11/5.-22-1-Normativne-vrednosti-casovno.pdf.

39. King LA, Priest KC, Salarian A, Pierce D, Horak FB. Comparing the Mini-BESTest with the Berg Balance Scale to evaluate balance disorders in Parkinson's disease. Parkinsons Dis. 2012;2012:375419; doi: 10.1155/2012/ 375419.

40. Chou CY, Chien CW, Hsueh IP, Sheu CF, Wang CH, Hsieh CL. Developing a short form of the Berg Balance Scale for people with stroke. Phys Ther. 2006;86(2):195204; doi: 10.1093/ptj/86.2.195.

41. Tsang CS, Liao LR, Chung RC, Pang MY. Psychometric properties of the Mini-Balance Evaluation Systems Test (Mini-BESTest) in community-dwelling individuals 
with chronic stroke. Phys Ther. 2013;93(8):1102-1115; doi: 10.2522/ptj.20120454.

42. Lemay JF, Nadeau S. Standing balance assessment in ASIA D paraplegic and tetraplegic participants: concurrent validity of the Berg Balance Scale. Spinal Cord. 2010;48(3):245-250; doi: 10.1038/sc.2009.119.

43. Paltamaa J, Sjögren T, Peurala SH, Heinonen A. Effects of physiotherapy interventions on balance in multiple sclerosis: a systematic review and meta-analysis of randomized controlled trials. J Rehabil Med. 2012;44(10): 811-823; doi: 10.2340/16501977-1047.

44. Hausdorff JM, Schweiger A, Herman T, Yogev-Seligmann G, Giladi N. Dual-task decrements in gait: contributing factors among healthy older adults. J Gerontol A Biol Sci Med Sci. 2008;63(12):1335-1343; doi: 10.1093/ gerona/63.12.1335.

45. Toulotte C, Thevenon A, Watelain E, Fabre C. Identification of healthy elderly fallers and non-fallers by gait analysis under dual-task conditions. Clin Rehabil. 2006;20(3): 269-276; doi: 10.1191/0269215506cr929oa.

46. Shumway-Cook A, Brauer S, Woollacott M. Predicting the probability for falls in community-dwelling older adults using the Timed Up \& Go Test. Phys Ther. 2000;80(9): 896-903; doi: 10.1093/ptj/80.9.896.

47. Gill TM, Williams CS, Tinetti ME. Assessing risk for the onset of functional dependence among older adults: the role of physical performance. J Am Geriatr Soc. 1995; 43(6):603-609; doi: 10.1111/j.1532-5415.1995.tb07192.x.

48. Arnau A, Espaulella J, Serrarols M, Canudas J, Formiga F, Ferrer M. Risk factors for functional decline in a population aged 75 years and older without total dependence: a one-year follow-up. Arch Gerontol Geriatr. 2016;65:239-247; doi: 10.1016/j.archger.2016.04.002.

49. Hofheinz M, Schusterschitz C. Dual task interference in estimating the risk of falls and measuring change: a comparative, psychometric study of four measurements. Clin Rehabil. 2010;24(9):831-842; doi: 10.1177/02692155 10367993.

50. Geiger RA, Allen JB, O'Keefe J, Hicks RR. Balance and mobility following stroke: effects of physical therapy interventions with and without biofeedback/forceplate training. Phys Ther. 2001;81(4):995-1005.

51. O'Hoski S, Winship B, Herridge L, Agha T, Brooks D, Beauchamp MK, et al. Increasing the clinical utility of the BESTest, mini-BESTest, and brief-BESTest: normative values in Canadian adults who are healthy and aged 50 years or older. Phys Ther. 2014;94(3):334-342; doi: 10.2522/ptj.20130104. 